Folia phoniat. 1973;25:397-398

\title{
In memoriam Jean Tarneaud
}

Le 29 juillet 1972, le Docteur Jean Tarneaud nous quittait après une longue et pénible maladie. Créateur de la Spécialité phoniatrique, il fut le fondateur de la Société Française de Phoniatrie. Né le 6 Janvier 1888, à Jarnac, il passe sa these en 1917 et se consacre totalement à $\Gamma$ étude de la Physiologie, de la Pathologie et de la Thérapeutique de la voix. C'est à ce titre qu'il acquiert le poste de laryngologiste du Conservatoire National de Musique, de Chef de Travaux de Phoniatrie à la Faculté de Médecine de Paris et de Phoniatrie de ГHôpital Bellan.

Depuis 1933, il avait institué une série de Cours annuels sur la Voix, la Parole et le Chant. II participa largement au Cours International de Phono-logie et de Phoniatrie organise par le Professeur Aubin en 1953.

Ses publications les plus importantes ont porté sur la pathologie et la thérapeutique vocales. Parmi celles-ci, on peut citer: «Le nodule de la corde vocale», «La Stroboscopie du Larynx», «Les maladies de la Voix», "Voix et Parole», et la plus connue de tous est son «Traité pratique de Phonologie et Phoniatrie», en collaboration avec Madame Borel-Maisonny. Auteur de 85 communications, il participa à de nombreux Congrès en France et à $\Gamma$ étranger, sa renommee s'étendit bien au-delà de $\Gamma$ Europe et il demeure pour tous ceux qui s'intéressent au problème de la Voix, le «Père de la Phoniatrie ».

Depuis plusieurs années, il avait cessé de paraître lors des manifestations scientifiques, retenu à son domicile par la maladie. II y reçevait ses amis et élèves avec un sens de Гaccueil qui lui était particulier.

Tous ceux qui ont fréquenté «Lariboisière », se souviennent de ses exposes cliniques, de son diagnostic sûr et precis, de son immense experience qu'il avait acquise au cours des années. Deux graves interventions chirurgicales, pratiquées coup sur coup, ébranlèrent sa santé déjà fragile, et c'est avec le

398

In memoriam Jean Tarneaud

courage et la sérénité d'un grand croyant qu'il s'éteignit en cette fin de juillet 1972.

A Madame Tarneaud qui fut sa collaboratrice de tous les jours, à ses enfants, nous adressons nos sentiments de profonde emotion et Tassurance que nous prenons part à leur immense chagrin.

S. Son souvenir demeurera dans la pensée de tous ceux qui Гont connu et qui lui adressent aujourd'hui un ultime témoignage de fidélité.

B. Vallancien 